\title{
Esophageal Involvement and Determinants of Perception of Esophageal Symptoms Among South Koreans With Systemic Sclerosis
}

\begin{abstract}
Joon Seong Lee, ${ }^{1}$ Hyun-Sook Kim, ${ }^{2}$ Jung Rock Moon, ${ }^{1}$ Tom Ryu, ${ }^{1}$ Su Jin Hong, ${ }^{3}$ Young Sin Cho, ${ }^{4}$ Junseok Park, ${ }^{1}$ and Tae Hee Lee ${ }^{1 *}$
${ }^{1}$ Institute for Digestive Research, Digestive Disease Center, Soonchunhyang University College of Medicine, Seoul, Korea; ${ }^{2}$ Department of Rheumatology, Soonchunhyang University College of Medicine, Seoul, Korea; ${ }^{3}$ Department of Internal Medicine, Soonchunhyang University College of Medicine, Bucheon, Gyeonggi-do, Korea; and ${ }^{4}$ Division of Gastroenterology, Cheonan Hospital, Soonchunhyang University College of Medicine, Cheonan, Chungcheongnam-do, Korea
\end{abstract}

\section{Background/Aims}

Our study aims to characterize esophageal motor function; evaluate the relationships among esophagogastroduodenoscopy (EGD), high-resolution manometry (HRM), and 24-hour esophageal multichannel intraluminal impedance monitoring combined with pHmetry (MII-pH); and elucidate the determinants of esophageal symptom perception in South Koreans with systemic sclerosis (SSc).

\section{Methods}

We reviewed prospectively collected HRM $(n=46)$, EGD $(n=41)$, and MII-pH $(n=37)$ data from 46 consecutive patients with SSc (42 females; mean age 50.1 years) who underwent esophageal tests between June 2013 and September 2018.

\section{Results}

The most common HRM diagnosis was normal (39.1\%), followed by ineffective esophageal motility (23.9\%) and absent contractility (21.7\%). Erosive esophagitis was observed in $12.2 \%$ of total SSc patients, with a higher frequency in patients with absent contractility than those with normal motility (44.5\% vs $0.0 \%, P=0.01)$. Pathologic acid exposure was observed in 6 patients $(20.0 \%)$ and positive symptom association in 18 patients $(60.0 \%)$ in MII-pH tests of symptomatic patients. The proportion of SSc patients with esophageal symptoms not explained by reflux or mucosal or motor esophageal abnormalities was 33.0\%.

\section{Conclusions}

Esophageal involvement among South Koreans with SSc was characterized by heterogeneous motility patterns, with a higher prevalence of normal motility and lower prevalence of erosive esophagitis. Reflux hypersensitivity or functional heartburn might be partly attributed to the perception of esophageal symptoms in SSc patients who have neither gastroesophageal reflux disease nor esophageal dysmotility.

(J Neurogastroenterol Motil 2020;26:477-485)

Key Words

Diagnosis; Esophageal motility disorders; Esophagus; Manometry; Scleroderma

Received: August 6, 2019 Revised: March 9, 2020 Accepted: July 3, 2020

(.) This is an Open Access article distributed under the terms of the Creative Commons Attribution Non-Commercial License (http://creativecommons. org/licenses/by-nc/4.0) which permits unrestricted non-commercial use, distribution, and reproduction in any medium, provided the original work is properly cited.

*Correspondence: Tae Hee Lee, MD, PhD Institute for Digestive Research, Digestive Disease Center, Soonchunhyang University College of Medicine, 59, Daesagwan-ro, Hannam-Dong, Yongsan-Gu, Seoul 140-743, Korea Tel: +82-2-710-3084, Fax: +82-2-709-9696, E-mail: iman0825@schmc.ac.kr

Joon Seong Lee and Hyun-Sook Kim contributed equally to this work. 


\section{Introduction}

The prevalence of systemic sclerosis (SSc) has been reported to be race specific, ${ }^{1}$ with a lower prevalence in the white (224.7/ million) than the black (315/million) population. In a survey based on the public health system database, a lower prevalence (53/million) was observed in the Japanese population. ${ }^{2}$ A recent Korean nationwide population-based study indicated that the prevalence was 77.7/million population. ${ }^{3}$ A single-center, predominantly white, SSc cohort in Canada reported ethnic variation in certain clinical features such as esophageal dysmotility and calcinosis. ${ }^{4}$ Specifically, East Asians had esophageal dysmotility (69.0\%) less frequently compared with the white population $(88.0 \%){ }^{4}$

Esophageal manometry is the gold standard to evaluate esophageal dysmotility. The classic sclerosis esophagus is defined when SSc patients have no peristalsis in the distal esophagus and hypotensive lower esophageal sphincter (LES) pressure on manometric examination. Recently, high-resolution manometry (HRM) has replaced conventional manometry because of better diagnostic accuracy and reproducibility. A few HRM studies have evaluated esophageal involvement in Western SSc patients. ${ }^{5}$ The classic sclerosis esophagus was found in as many as $55.0 \%$ of Western SSc patients. Crowell et $\mathrm{al}^{6}$ reported that this classic esophageal manometric abnormality was found in only one-third of patients, and normal motility was found in $26.0 \%$, implying a heterogeneous spectrum of esophageal dysmotility among Western SSc patients. Esophageal dysmotility in East Asian SSc patients has not been determined based on HRM examination.

Ethnic and geographical differences are closely related to the prevalence of erosive esophagitis among the general population. ${ }^{7.8}$ The prevalence of erosive esophagitis is reportedly higher in Western populations than in East Asian populations. The estimated prevalence of erosive esophagitis in Western patients with SSc is $30.0-40.0 \%$, although rates up to $60.0 \%$ have been reported. ${ }^{9-12}$ Its prevalence among East Asian patients with SSc is unknown.

Most Western SSc studies have indicated that the presence of esophageal symptoms is not a reliable predictor of esophageal dysmotility. ${ }^{12-15}$ Symptoms of gastroesophageal reflux have been reported to be a poor indicator of erosive esophagitis in Western SSc patients. ${ }^{10}$ Little is known about the associations of esophageal symptoms with esophageal dysmotility and erosive esophagitis in East Asian patients with SSc. The perception of esophageal symptoms in some SSc patients is explained by reflux or mucosal or esophageal dysmotility. However, to our knowledge, the determi- nants of esophageal symptom perception in SSc patients who have neither gastroesophageal reflux disease nor dysmotility have never been reported.

To develop a better understanding of esophageal involvement in South Koreans with SSc, the specific aims of this study are to characterize esophageal motor function; evaluate the relationships among HRM, esophagogastroduodenoscopy (EGD), and 24hour esophageal multichannel intraluminal impedance monitoring combined with $\mathrm{pH}$-metry (MII-pH) data; and elucidate the determinants of esophageal symptom perception.

\section{Materials and Methods}

\section{Patient Characteristics and Ethics Statement}

Consecutive SSc patients referred from the SSc clinic for esophageal manometry between June 2013 and September 2018 were included. SSc was diagnosed using the 2013 American College of Rheumatology SSc criteria. ${ }^{16} \mathrm{SSc}$ was categorized as limited cutaneous systemic disease (lcSSc) or diffuse cutaneous systemic disease (dcSSc) according to the distribution of skin involvement, as proposed by LeRoy et al. ${ }^{17}$ Patients with incomplete clinical assessments were excluded. Complete data were available for 46 patients (lcSSc, 26; dcSSc, 20) with consecutive HRM studies conducted between June 2013 and September 2018. Relevant data were collected on each patient, including age, sex, and body mass index (BMI), as well as clinical information. The study was approved by the institutional review boards of participating hospital (2019-04033-001) and informed consent was obtained from all participants.

\section{High-resolution Manometry Procedure}

A solid-state HRM assembly (Sierra Scientific Instruments, Given Imaging, Los Angeles, CA, USA) with 36 solid-state sensors spaced at $1-\mathrm{cm}$ intervals was used. We measured data on basal LES pressure, integrated relaxation pressure (IRP), distal contractile integral (DCI), and distal latency (DL) to classify esophageal motility disorders according to the Chicago classification of esophageal motility disorders, version 3.0. The esophagogastric junction (EGJ) contractile integral (EGJ-CI) was measured as reported previously by Gor et $\mathrm{al}^{18}$ from the landmark period. Hypotensive mean EGJ pressure at rest was defined as less than $13 \mathrm{mmHg}$. The combination of absent contractility and hypotensive EGJ pressure is defined as classic sclerosis esophagus. ${ }^{6}$ The multiple rapid swallow (MRS) test was assessed for complete deglutitive inhibition and optimal post-MRS contraction. Deglutitive inhibition was defined 
as incomplete if a contraction segment with an isobaric contour greater than $20 \mathrm{mmHg}$, length greater than $3 \mathrm{~cm}$, and DCI greater than $100 \mathrm{mmHg} \cdot \mathrm{sec} \cdot \mathrm{cm}$, was present during the MRS test. The post-MRS contraction after MRS was designated as suboptimal if the augmentation ratio (ie, the DCI after MRS divided by the median of the non-failed patients [ie, DCI > 100]) was less than 1 . An abnormal MRS response was defined as the presence of either incomplete deglutitive inhibition or suboptimal post-MRS contraction (Supplementary Figure).

\section{Esophagogastroduodenoscopy Examination}

EGD examinations were performed in $41 \mathrm{SSc}$ patients using the GIF-HQ290 or GIF-Q260 endoscope (Olympus Medical Systems Corp, Tokyo, Japan) with/without narrow band imaging by 2 gastroenterologists (T.H.L. and J.S.L.) at our center. Five patients in whom EGD was performed at an outside hospital were excluded from our analysis. A cervical inlet patch was identified as a well-circumscribed, pinkish-yellow area with a distinct border during white light endoscopy. Reflux esophagitis was defined as grade A or more severe, in accordance with the Los Angeles classification. ${ }^{19}$ The gastroesophageal flap valve, which is created by intraluminal extension of the angle of His, was graded I to IV according to the grading system recently described by Hill et al. ${ }^{20}$

\section{Multichannel Intraluminal Impedance Monitoring Combined With $\mathrm{pH}$-metry Procedure}

MII-pH examination (Sandhill Scientific, Inc, Highland Ranch, CO, USA) was performed at least 7 days after proton pump inhibitor withdrawal. The $\mathrm{pH}$ electrode was placed $5 \mathrm{~cm}$ above the upper margin of the manometrically defined LES, and esophageal impedance electrodes' values (z1, z2, z3, z4, z5, and z6) were determined at 6 sites $(3,5,7,9,15$, and $17 \mathrm{~cm}$ above the LES, respectively). The DeMeester score, acid exposure upright (\%), acid exposure recumbent (\%), acid exposure total (\%), bolus exposure upright (\%), bolus exposure recumbent $(\%)$, bolus exposure total (\%), proximal acid events, proximal nonacid events, proximal total events, distal acid reflux events, distal non-acid reflux events, and distal total reflux events were measured. ${ }^{21}$ Pathologic acid exposure (PAE) was defined when the distal esophageal acid exposure time was greater than $4.2 \%$ at a $\mathrm{pH}<4$ over 24 hours. Symptoms were considered associated with reflux if they occurred within a 2-minute window after onset of the reflux episode. ${ }^{21}$ Symptom association (SA) was considered positive if the symptom index was $50.0 \%$ or greater; SA probability was considered positive if it was $95.0 \%$ or greater. $^{22}$ All parameters were measured using Bio View Analysis software (Sandhill Scientific, Inc).

\section{Esophageal Symptoms}

Esophageal symptoms included heartburn, regurgitation, chest pain, dysphagia, globus sensation, and others (belching, cough, asthma, etc). Each symptom was classified as present or absent. If symptoms such as heartburn, regurgitation, chest pain, dysphagia, and globus sense were present, they were rated according to frequency and severity using a 5-point Likert scale (0-4). We asked patients to rate the frequency of their symptoms as follows: 0 , no symptoms; 1 , less than once per month; 2 , two to four times per month; 3 , one to six times per week; and 4, daily. The patients also rated the severity of their symptoms as follows: 0 , no symptoms; 1 , can be ignored with effort; 2, cannot be ignored but does not influence daily activities; 3 , cannot be ignored and limits concentration on daily activities; and 4, cannot be ignored and markedly limits daily activities, often requiring rest. The individual symptom score for each symptom was calculated as the product of the frequency and severity scores.

\section{Clinical Evaluation}

Generally, the disease duration in SSc studies is defined as the time elapsed since the onset of the first Raynaud's phenomenon. ${ }^{23}$ The modified Rodnan skin score (mRSS) is a measure of skin thickness and is used as a primary or secondary outcome measure in clinical trials of systemic sclerosis. ${ }^{24}$ Measurement of skin thickness is used as a surrogate for disease activity, severity, and mortality in dcSSc patients. ${ }^{24}$ In our study, mRSS was assessed by a rheumatology expert (H.S.K.). With respect to disease status in SSc patients, there is no gold standard instrument. However, the identification of organ damage has been used as a measure. Therefore, we evaluated the relationship between HRM metrics and the presence of interstitial lung disease.

\section{Statistical Methods}

Quantitative and qualitative data are presented as medians (interquartile range $[\mathrm{IQR}]$ ) and numbers (percentage), respectively. Comparisons of data from the HRM, EGD, and MII-pH tests were performed using the Mann-Whitney test and chi-squared test or Fisher's exact test when appropriate. The Spearman's correlation coefficient was used to analyze the relationship among the disease duration, mRSS, and HRM metrics. For multiple comparisons, $P$-values were adjusted by the Bonferroni procedure. A $P$-value $<$ 0.05 was considered statistically significant. 


\section{Results}

The SSc patients $(\mathrm{n}=46)$ were mostly women (91.3\%), with a median (IQR) age of 53.0 (42.8-58.3) years and BMI of 22.0 $(20.3-24.1) \mathrm{kg} / \mathrm{m}^{2}$. The $\mathrm{lcSSc}$ and dcSSc subtypes were diagnosed in $26(56.5 \%)$ and $20(43.5 \%)$ patients, respectively. There were 36 SSc patients $(78.3 \%)$ with any esophageal symptoms, with regurgitation $(16,34.8 \%)$ and globus sensation being the most commonly reported symptoms. Table 1 shows the baseline clinical characteristics of the patients with lcSSc and dcSSc.

Table 1. Baseline Characteristics of Patients With Limited or Diffuse Systemic Sclerosis

\begin{tabular}{|c|c|c|c|c|}
\hline Variables & $\operatorname{lcSSc}(n=26)$ & $\operatorname{dcSSc}(\mathrm{n}=20)$ & $P$-value ${ }^{\mathrm{a}}$ & Total $(\mathrm{N}=46)$ \\
\hline Female & $24(92.3)$ & $18(90.0)$ & 0.783 & $42(91.3)$ \\
\hline Age (yr) & $54.0(44.8-58.3)$ & $49.0(37.3-60.5)$ & 0.690 & $53.0(42.8-58.3)$ \\
\hline $\operatorname{BMI}\left(\mathrm{kg} / \mathrm{m}^{2}\right)$ & $21.9(20.1-24.2)$ & $22.1(20.5-23.9)$ & 0.973 & $22.0(20.3-24.1)$ \\
\hline \multicolumn{5}{|l|}{ Esophageal symptoms } \\
\hline Heartburn & $11(42.3)$ & $2(10.0)$ & 0.016 & $13(28.3)$ \\
\hline Regurgitation & $10(38.5)$ & $6(30.0)$ & 0.550 & $16(34.8)$ \\
\hline Chest pain & $10(38.5)$ & $4(20.0)$ & 0.177 & $14(30.4)$ \\
\hline Dysphagia & $7(26.9)$ & $4(20.0)$ & 0.585 & $11(23.9)$ \\
\hline Globus & $8(30.8)$ & $8(40.0)$ & 0.515 & $16(34.8)$ \\
\hline Belching & $8(30.8)$ & $4(20.0)$ & 0.410 & $12(26.1)$ \\
\hline Cough & $6(30.8)$ & $5(25.0)$ & 0.667 & $11(23.9)$ \\
\hline Asthma & $0(0.0)$ & $2(10.0)$ & 0.184 & $2(4.3)$ \\
\hline EGD assessment & $24(92.3)$ & $17(85.0)$ & 0.640 & $41(89.1)$ \\
\hline CIPs & $1(4.2)$ & $0(0.0)$ & $>0.999$ & $1(2.4)$ \\
\hline Erosive esophagitis & $1(4.2)$ & $4(23.5)$ & 0.141 & $5(12.2)$ \\
\hline GEFV (III-IV) & $3(12.5)$ & $5(29.4)$ & 0.241 & $8(19.5)$ \\
\hline MII-pH assessment & $24(92.3)$ & $13(65.0)$ & 0.029 & $37(80.4)$ \\
\hline
\end{tabular}

${ }^{a}$ Comparison between limited cutaneous systemic sclerosis (lcSSc) and diffuse cutaneous systemic sclerosis (dcSSc).

BMI, body mass index; EGD, esophagogastroduodenoscopy; CIP, cervical inlet patch; GEFV, gastroesophageal flap valve; MII-pH, multichannel intraluminal impedance monitoring combined with $\mathrm{pH}$-metry.

Values are represented as numbers (\%) or medians (interquartile range).

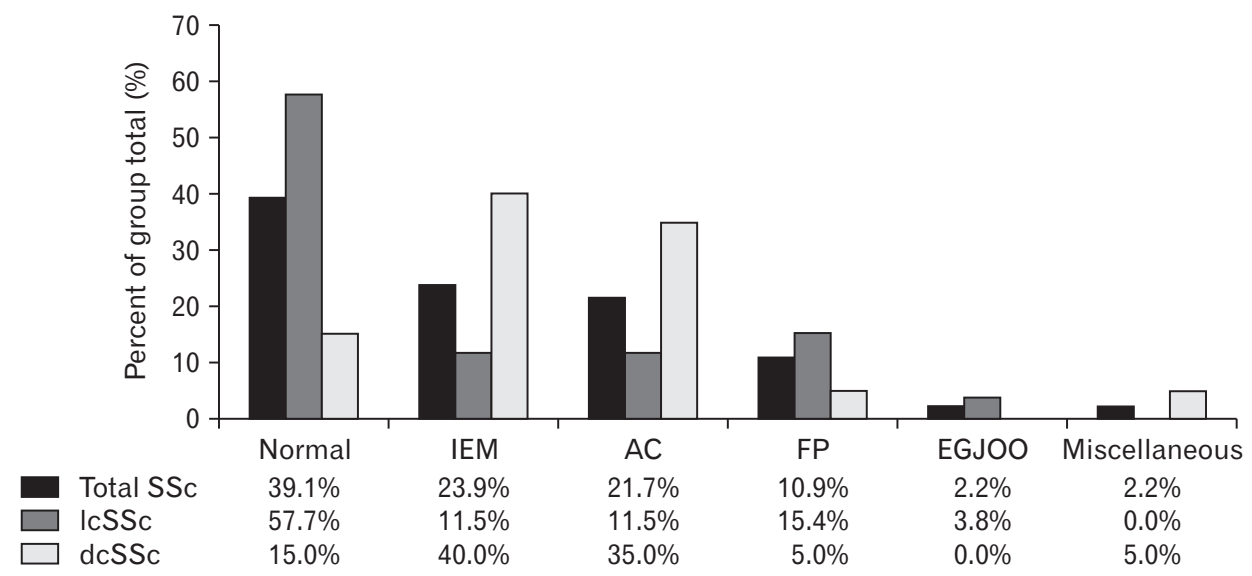

Figure. High-resolution manometry (HRM) diagnosis based on the Chicago classification of esophageal motility disorders, version 3.0. IEM, ineffective esophageal motility; AC, absent contractility; FP, fragmented peristalsis; EGJOO, esophagogastric junction outflow obstruction. Miscellaneous motility indicates compartmentalized pressurization; SSc, systemic sclerosis; IcSSC, limited cutaneous systemic sclerosis; dcSSc, diffuse cutaneous systemic sclerosis. 


\section{High-resolution Manometry Diagnosis Using the Chicago Classification of Esophageal Motility Disorders, Version 3.0}

The most common diagnosis by HRM among the total SSc patients was normal (39.1\%), followed by ineffective esophageal motility (IEM, 23.9\%), absent contractility (AC, 21.7\%), fragmented peristalsis (FP, 10.9\%), and EGJ outflow obstruction (EGJOO, 2.2\%) (Figure). One patient had an abnormal HRM finding that was not addressed by the Chicago classification of esophageal motility disorders, version 3.0, but was classified as compartmentalized pressurization. Hypotensive EGJ pressure was found in 16 patients $(34.8 \%)$. Importantly, classic sclerosis esophagus was observed in only 7 patients (15.2\%). The distributions of normal, minor esophageal motility disorders (IEM, FP, and compartmentalized pressurization) and major motility disorders differed signifi- cantly between the lcSSc and dcSSc subtypes $(P=0.013$; Table 2).

\section{High-resolution Manometry Metrics and Multiple Rapid Swallow}

The 1cSSc subtype had a significantly higher median DCI $(872.1 \mathrm{mmHg} \cdot \mathrm{sec} \cdot \mathrm{cm})$ than that of the $\mathrm{dcSSc}$ subtype (90 $\mathrm{mmHg} \cdot \mathrm{sec} \cdot \mathrm{cm}, P=0.024)$. Other metrics such as EGJ pressure, 4-second IRP (4s-IRP), DL, and EGJ-CI were similar in the 2 subtypes.

All SSc patients who performed the MRS test had abnormal MRS findings (97.8\%) except for $1 \mathrm{dcSSc}$ patient who did not perform the test. Incomplete inhibition during the MRS test was observed in $28.9 \%$ and suboptimal post-MRS contraction in $88.9 \%$. The median (IQR) DCI ratio of the total SSc patients was $0.0(0.0$ 0.1 ), with a median (IQR) 4s-IRP during the MRS test of 4.9 (2.0-6.9) $\mathrm{mmHg}$. The median DCI ratio was significantly lower in

Table 2. High-resolution Manometry Diagnosis Based on the Chicago Classification of Esophageal Motility Diagnosis, Version 3.0, and Highresolution Manometry Metrics in Patients With Limited or Diffuse Systemic Sclerosis

\begin{tabular}{|c|c|c|c|c|}
\hline HRM & $\operatorname{lcSSc}(\mathrm{n}=26)$ & $\operatorname{dcSSc}(n=20)$ & $P$-value ${ }^{\mathrm{a}}$ & Total $(\mathrm{N}=46)$ \\
\hline Diagnosis & & & 0.013 & \\
\hline Normal & $15(57.7)$ & $3(15.0)$ & & $18(39.1)$ \\
\hline Minor motility & $7(26.9)$ & $10(50.0)$ & & $17(37.0)$ \\
\hline IEM & 3 & 8 & & 11 \\
\hline Fragmented peristalsis & 4 & 1 & & 5 \\
\hline Compartmentalized pressurization & 0 & 1 & & 1 \\
\hline Major motility & $4(15.4)$ & $7(35.0)$ & & $11(23.9)$ \\
\hline Absent contractility & 3 & 7 & & 10 \\
\hline EGJOO & 1 & 0 & & 1 \\
\hline \multicolumn{5}{|l|}{ Metrics } \\
\hline Median EGJ pressure (mmHg) & $19.5(10.1-27.4)$ & $16.6(10.2-26.2)$ & 0.634 & $18.9(10.4-26.8)$ \\
\hline Median IRP $(\mathrm{mmHg})$ & $6.1(3.8-10.8)$ & $6.6(4.7-8.2)$ & 0.868 & $6.5(3.9-9.3)$ \\
\hline Median DCI (mmHg·sec $\cdot \mathrm{cm})$ & $872.1(118.2-1415.1)$ & $90(0-729.7)$ & 0.024 & $520(0.0-1340.0)$ \\
\hline Median $\mathrm{DL}^{\mathrm{b}}(\mathrm{sec})$ & $6.3(5.6-7.2)$ & $7.6(6.3-8.4)$ & 0.051 & $6.7(5.7-7.6)$ \\
\hline Median EGJ-CI (mmHg/cm) & $18.8(8.6-33.8)$ & $20(10.7-32.6)$ & 0.842 & $19.3(9.7-32.9)$ \\
\hline \multicolumn{5}{|l|}{ MRS test ${ }^{c}$} \\
\hline Abnormal MRS & $26(100.0 \%)$ & $18(94.7)$ & 0.422 & $44(97.8)$ \\
\hline Incomplete inhibition during MRS & $10(38.5)$ & $3(15.8)$ & 0.097 & $13(28.9)$ \\
\hline Suboptimal post-MRS contraction & $22(84.6)$ & $18(94.7)$ & 0.378 & $40(88.9)$ \\
\hline Median post-MRS/SS DCI ratio & $0.5(0.0-1.1)$ & $0.0(0.0-0.1)$ & 0.006 & $0.0(0.0-0.95)$ \\
\hline Median 4s-IRP during MRS (mmHg) & $5.1(2.1-8.0)$ & $4.7(1.9-6.3)$ & 0.505 & $4.9(2.0-6.9)$ \\
\hline
\end{tabular}

${ }^{\mathrm{a} C o m p a r i s o n ~ b e t w e e n ~ l i m i t e d ~ c u t a n e o u s ~ s y s t e m i c ~ s c l e r o s i s ~(l c S S c) ~ a n d ~ d i f f u s e ~ c u t a n e o u s ~ s y s t e m i c ~ s c l e r o s i s ~(d c S S c) . ~}$

${ }^{\text {b }}$ Patients with absent contractility were excluded from this analysis.

${ }^{c}$ One dcSSc patient did not perform the multiple rapid swallow (MRS) test due to dysphagia.

HRM, high-resolution manometry; IEM, ineffective esophageal motility; EGJOO, esophagogastric junction outflow obstruction; EGJ, esophagogastric junction; EGJ-CI, EGJ-contractile integral; SS, single swallow; DCI, distal contractile integral; 4s-IRP, 4-second integrated relaxation pressure.

Values are represented as numbers (percentage) or medians (interquartile range). 
Table 3. Motility Patterns and Erosive Esophagitis Based on Both Pathologic Acid Exposure and Symptom Association in Symptomatic Systemic Sclerosis Patients

\begin{tabular}{|c|c|c|c|}
\hline Variables & $\begin{array}{l}\mathrm{PAE}+ \\
(\mathrm{n}=6)\end{array}$ & $\begin{array}{c}\mathrm{PAE}-\mathrm{SA}+ \\
(\mathrm{n}=13)\end{array}$ & $\begin{array}{c}\mathrm{PAE}-\mathrm{SA}- \\
(\mathrm{n}=11)\end{array}$ \\
\hline Proportion & $20.0 \%$ & $43.0 \%$ & $37.0 \%$ \\
\hline \multicolumn{4}{|c|}{ HRM diagnosis (Chicago classification of motility diagnosis, version3.0) } \\
\hline Major motility disorders & $3(50.0)$ & $3(23.1)$ & $1(9.1)$ \\
\hline Minor motility disorders and normal & $1(50.0)$ & $10(76.9)$ & $10(90.9)$ \\
\hline Erosive esophagitis $^{a}$ & $4(66.7)^{\mathrm{b}}$ & $0(0.0)$ & $0(0.0)$ \\
\hline
\end{tabular}

${ }^{a}$ Endoscopy was not performed in two symptomatic systemic sclerosis patients who were pathologic acid exposure (PAE) - and symptom association $(\mathrm{SA})+$.

${ }^{\mathrm{b}}$ Adjusted $P$-value $<0.001$, after Bonferroni correction, comparison among patients with $\mathrm{PAE}+, \mathrm{PAE}-\mathrm{SA}+$, or $\mathrm{PAE}-\mathrm{SA}-$.

PAE was defined when the distal esophageal acid exposure time was more than $4.2 \%$ at a $\mathrm{pH}<4$ over 24 hours.

SA was considered positive if the symptom index was $50.0 \%$ or greater; SA probability was considered positive if it was $95.0 \%$ or greater.

Values are represented as numbers (percentage).

the dcSSc patients than in the $\mathrm{lcSSc}_{\mathrm{c}}$ patients ( 0.0 vs $\left.0.5, P=0.006\right)$ (Table 2).

EGJ pressure positively correlated with the DCI (rho $=0.445$, $P=0.002)$. Disease duration negatively correlated with mean EGJ pressure (rho $=-0.392, P=0.007)$ and mean $\mathrm{DCI}($ rho $=-0.427$, $P=0.003)$. However, neither mean DL nor mean IRP correlated with disease duration. Of the HRM metrics, only the DCI and EGJ pressure reflected disease duration. We found that none of our HRM metrics reflected disease activity as measured by mRSS. None of the HRM parameters were related to the presence of interstitial lung disease.

\section{Endoscopic Diagnosis}

Erosive esophagitis was observed in $12.2 \%$ of total SSc patients, and the rate of erosive esophagitis was similar in the lcSSc and dcSSc patients (Table 1).

The associations among demographics (ie, sex, age, and BMI), SSc subtype, and HRM data were further evaluated in SSc patients with respect to the presence of erosive esophagitis. Demographics and SSc subtypes were comparable between the 2 groups (Supplementary Table 1). However, more patients with erosive esophagitis had AC compared with patients without erosive esophagitis $(80.0 \%$ vs $13.9 \%, P=0.006)$. A lower median 4s-IRP $(1.8 \mathrm{mmHg}$ vs 6.6 $\mathrm{mmHg}, P=0.024)$ and lower DCI $(0.0 \mathrm{mmHg} \cdot \mathrm{sec} \cdot \mathrm{cm}$ vs 737.4 $\mathrm{mmHg} \cdot \mathrm{sec} \cdot \mathrm{cm}, P=0.004)$ were found in patients with erosive esophagitis compared with patients without erosive esophagitis. The proportion of abnormal MRS tests was similar between patients with and those without erosive esophagitis.

\section{Normal Motility Versus Absent Contractility in Systemic Sclerosis Patients}

The association among demographics, SSc type, esophageal symptoms, and endoscopic findings was further assessed in SSc patients with AC compared with those with normal motility (Supplementary Table 2). The rate of lcSSc was higher in patients with normal motility than in those with $\mathrm{AC}(85.3 \%$ vs $30.0 \%, P=$ 0.005). The presence of each esophageal symptom did not differ significantly between patients with $\mathrm{AC}$ and those with normal motility.

\section{Multichannel Intraluminal Impedance Monitoring Combined With pH-metry Test in Symptomatic Systemic Sclerosis Patients}

The MII-pH test was performed in 30 of 36 (83.0\%) symptomatic patients with SSc. PAE was observed in 6 patients (20.0\%), and positive SA in 18 patients $(60.0 \%$ ) (Table 3 ). The proportion of SSc patients with esophageal symptoms not explained by reflux or mucosal or motor esophageal abnormalities was $33.0 \%$. The symptomatic patients (37.0\%) had negative PAE and SA, which was suggestive of functional heartburn/chest pain. Only one of these patients had a major motility disorder (ie, EGJOO) and erosive esophagitis was not found. Other symptomatic patients (43.0\%) had negative PAE and positive $\mathrm{SA}$, which was suggestive of reflux hypersensitivity. Major motility disorders were observed in 3 patients (23.1\%; negative $\mathrm{PAE}$ and positive $\mathrm{SA}$ ), and erosive esophagitis was not observed. Esophageal symptoms in these patients were partly explained by reflux hypersensitivity.

There were no significant differences in the median acid expo- 
sure upright, recumbent, or total time between the lcSSc and dcSSc patients (Supplementary Table 3).

\section{Discussion}

This is the first study to examine esophageal involvement based on HRM and EGD findings and to elucidate the associations of the esophageal symptoms between esophageal dysmotility and erosive esophagitis in South Koreans with SSc. Our findings provide unique insight into the perception of esophageal symptoms, which can lead to optimal clinical management of SSc patients who have neither dysmotility nor erosive esophagitis.

There are heterogeneous esophageal motility disorders with a higher prevalence of normal contraction detected by HRM. Specifically, the most common HRM diagnosis among the total SSc patients was normal (39.1\%) followed by IEM (23.9\%), AC (21.7\%), FP (10.9\%), and EGJOO (2.2\%). Classic sclerosis esophagus was found in only approximately $15.0 \%$ of our SSc patients. Recent HRM studies of Western patients with SSc demonstrated diverse esophageal motility patterns, where AC was the most prevalent. ${ }^{6,25}$ On one hand, our findings of diverse esophageal motility patterns urge clinicians to keep an open mind about esophageal dysmotility in $\mathrm{SSc}$ patients. On the other hand, our study was designed as a cross-sectional study. It may be described as a snapshot of HRM findings in our population at a single point in time. Therefore, some HRM findings, such as the presence of normal or minor esophageal motility disorders, might change over time. In our study, heterogeneity in the spectrum of esophageal motility disorders may reflect progression of esophageal smooth muscle involvement (ie, a movement along the disease continuum).

MRS during the HRM test is a provocation test to assess peristaltic reserve. In our study, almost all SSc patients had abnormal MRS findings suggestive of impaired peristaltic reserve. This was the most common esophageal motility finding among our SSc patients, which is in line with a previous Western HRM study. ${ }^{26}$ In addition, impaired peristaltic reserve was observed in all of the SSc patients with normal motility in a standard HRM study.

Our observations imply that South Koreans with SSc had a low frequency of erosive esophagitis compared with Western studies, in which the estimated prevalence was $30.0-40.0 \% .^{9-12}$ The factors underlying the significant racial difference in the prevalence of erosive esophagitis may include differences in the frequencies of $\mathrm{He}$ licobacter pylori infection, ${ }^{27}$ gastric acid secretion, ${ }^{28}$ dietary habits, obesity prevalence, and unspecified genetic factors that predispose to erosive esophagitis. ${ }^{29}$ In the present study, erosive esophagitis was related to AC but not to esophageal symptoms.

Lahcene et $\mathrm{al}^{30}$ reported that there was significant difference in the frequency of erosive esophagitis between SSc patients with esophageal motility disorders and patients without esophageal motility disorders $(44.6 \%$ vs $8.0 \%, P<0.001)$. Aggarwal et al ${ }^{31}$ reported that diverse esophageal motility disorders were found in systemic sclerosis. Their study also indicated that the prevalence of erosive esophagitis was higher in $\mathrm{SSc}$ patients with $\mathrm{AC}$ than in those with normal motility ( $47.9 \%$ vs $11.8 \%, P=0.030) .{ }^{31}$ In our study, erosive esophagitis was more prevalent in patients with AC than in those with normal motility $(44.4 \%$ vs $0.0 \%, P=0.010)$. Our data also indicated that lower median 4s-IRPs $(1.8 \mathrm{mmHg}$ vs $6.6 \mathrm{mmHg}, P=0.024)$ and a lower DCI $(0.0 \mathrm{mmHg} \cdot \mathrm{sec} \cdot \mathrm{cm}$ vs $737.4 \mathrm{mmHg} \cdot \mathrm{sec} \cdot \mathrm{cm}, P=0.004)$ were found in patients with erosive esophagitis compared with patients without erosive esophagitis. The prevalence of erosive esophagitis in our SSc patients with AC was $44.0 \%$ and lies within the range of previous studies. Given our results and those of previous studies, we conclude that esophageal dysmotility contributes to GERD in SSc patients.

Our study indicate that severe esophageal dysmotility such as $\mathrm{AC}$ is related to the presence of erosive esophagitis but not to the presence or severity of esophageal symptoms. Surprisingly, we detected normal acid exposure and positive SA on the MII-pH test, suggesting reflux hypersensitivity, in $43.0 \%$ of all 30 symptomatic patients. In addition, $37.0 \%$ of all symptomatic SSc patients had normal acid exposure and negative SA, suggestive of functional heartburn/chest pain or other extra-esophageal causes. Our observations imply that reflux hypersensitivity and functional heartburn/ chest pain may play major roles in esophageal symptom development in a subset of SSc patients. These conditions are recognized as separate entities in the GERD spectrum and are primarily treated with neuromodulators and or psychologic interventions. Our observations provide unique and much-needed insight into the pathophysiology of esophageal symptoms, which can lead to the optimal clinical management of SSc patients.

In our study, there were no significant differences between the 2 groups in any of the baseline characteristics except for heartburn. However, significant differences in the distribution of normal, minor esophageal motility disorders, and major motility disorders were observed. In addition, patients with dcSSc had a significantly lower median DCI than those with 1cSSc. There is controversy over the relationship between SSc subtype and esophageal dysmotility (Supplementary Table 4). ${ }^{6,30,32-38}$ Some studies show no relationship. ${ }^{6,32}$ Others find that esophageal motility disorders are more frequent and more severe in patients with dcSSc. ${ }^{33-35}$ 
Limitations of our study include a relatively small sample size, its retrospective nature, and a lack of controls (ie, Western SSc patients). Future prospective multi-national studies including MII-pH data will help further reveal the differences in esophageal involvement between South Koreans and Western SSc patients and provide clear knowledge regarding the determinants of esophageal symptom perception.

In conclusion, esophageal involvement in South Koreans with SSc was characterized by heterogeneous motility patterns with a higher prevalence of normal motility and a lower prevalence of erosive esophagitis. The perception of esophageal symptoms may be partly explained by reflux hypersensitivity and functional heartburn/ chest pain in SSc patients who have neither gastroesophageal reflux disease nor esophageal dysmotility.

\section{Supplementary Materials}

Note: To access the supplementary tables and figure mentioned in this article, visit the online version of Journal of Neurogastroenterology and Motility at http://www.jnmjournal.org/, and at https:// doi.org/10.5056/jnm19148.

Financial support: This work was supported by the Soonchunhyang University Research Fund.

\section{Conflicts of interest: None.}

Author contributions: Study concept and design: Joon Seong Lee and Tae Hee Lee; data collection and/or processing: HyunSook Kim and Tae Hee Lee; statistical analysis: Tae Hee Lee; writing of manuscript: Joon Seong Lee, Hyun-Sook Kim, Tae Hee Lee; review the results and discussion of the data: Jung Rock Moon, Tom Ryu, Su Jin Hong, Young Sin Cho, and Junseok Park; and critical reviews and revision: Tae Hee Lee. All authors approved the final submission.

\section{References}

1. Chifflot H, Fautrel B, Sordet C, Chatelus E, Sibilia J. Incidence and prevalence of systemic sclerosis: a systematic literature review. Semin Arthritis Rheum 2008;37:223-235.2.

2. Tamaki T, Mori S, Takehara K. Epidemiological study of patients with systemic sclerosis in Tokyo. Arch Dermatol Res 1991;283:366-371.

3. Kang GW, Jung KH, Lee YS, et al. Incidence, prevalence, mortality and causes of death in systemic sclerosis in Korea: a nationwide populationbased study. Br J Dermatol 2018;178:e37-e39.

4. Al-Sheikh H, Ahmad Z, Johnson SR. Ethnic variations in systemic scle- rosis disease manifestations, internal organ involvement, and mortality. J Rheumatol 2019;46:1103-1108.

5. Denaxas K, Ladas SD, Karamanolis GP. Evaluation and management of esophageal manifestations in systemic sclerosis. Ann Gastroenterol 2018;31:165-170.

6. Crowell MD, Umar SB, Griffing WL, Dibaise KJ, Kacy BE, Vela MF. Esophageal motor abnormalities in patients with sclerosis: heterogeneity, risk factors, and effects on quality of life. Clin Gastroenterol and Hepatol 2017; 15:207-213, e1.

7. Kang JY. Systematic review: geographical and ethnic differences in gastro-oesophageal reflux disease. Aliment Pharmacol Ther 2004;20:705717.

8. Jung HK. Epidemiology of gastroesophageal reflux disease in Asia: a systematic review. J Neurogastroenterol and Motil 2011;17:14-27.

9. Marie I, Ducrotte P, Denis P, Hellot MF, Levesque H. Oesophageal mucosal involvement in patients with systemic sclerosis receiving proton pump inhibitor therapy. Aliment Pharmacol Ther 2006;24:1593-1601.

10. De Castro Parga ML, Alonso P, García Porrua C, Prada JI. [Esophageal mucosal lesions and sclerosis: prevalence, symptoms and risk factors.] Rev Esp Enferm Dig 1996;88:93-98. [Spanish]

11. D'Angelo WA, Fries JF, Masi AT, Shulman LE. Pathologic observations in systemic sclerosis (scleroderma). A study of fifty-eight autopsy cases and fifty-eight matched controls. Am J Med 1969;46:428-440.

12. Zamost BJ, Hirschberg J, Ippoliti AF, Furst DE, Clements PJ, Weinstein WM. Esophagitis in scleroderma. Prevalence and risk factors. Gastroenterology 1987;92:421-428.

13. Lock G, Holstege A, Lang B, Schölmerich J. Gastrointestinal manifestations of progressive systemic sclerosis. Am J Gastroenterol 1997;92:763771.

14. Weihrauch TR, Korting GW. Manometric assessment of oesophageal involvement in progressive systemic sclerosis, morphoea and Raynaud's disease. Br J Dermatol 1982;107:325-332.

15. Klein HA, Wald A, Graham TO, Campbell WL, Steen VD. Comparative studies of esophageal function in systemic sclerosis. Gastroenterology 1992;102:1551-1556.

16. van den Hoogen F, Khanna D, Fransen J, et al. 2013 classification criteria for systemic sclerosis: an American College of Rheumatology/European League against Rheumatism collaborative initiative. Arthritis Rheum 2013;65:2737-2747

17. LeRoy EC, Black C, Fleischmajer R, et al. Sclerosis (systemic sclerosis): classification, subsets and pathogenesis. J Rheumatol 1988;15:202-205.

18. Gor P, Li Y, Munigala S, Patel A, Bolkhir A, Gyawali CP. Interrogation of esophagogastric junction barrier function using the esophagogastric junction contractile integral: an observational cohort study. Dis Esophagus 2016;29:820-828.

19. Armstrong D, Bennett JR, Blum AL, et al. The endoscopic assessment of esophagitis: a progress report on observer agreement. Gastroenterology 1996;111:85-92.

20. Hill LD, Kozarek RA, Kraemer SJ, et al. The gastroesophageal flap valve: in vitro and in vivo observations. Gastrointest Endosc 1996;44:541547.

21. Shay S, Tutuian R, Sifrim D, et al. Twenty-four hour ambulatory simul- 
taneous impedance and $\mathrm{pH}$ monitoring: a multicenter report of normal values from 60 healthy volunteers. Am J Gastroenterol 2004;99:10371043.

22. Kushnir VM, Sathyamurthy A, Drapekin J, Gaddam S, Sayuk GS, Gyawali CP. Assessment of concordance of symptom reflux association tests in ambulatory $\mathrm{pH}$ monitoring. Aliment Pharmacol Ther 2012;35:1080-1087.

23. Della Rossa A, Valentini G, Bombardieri S, et al. European multicentre study to define disease activity criteria for systemic sclerosis. I. Clinical and epidemiological features of 290 patients from 19 centres. Ann Rheum Dis 2001;60:585-591.

24. Khanna D, Furst DE, Clements PJ, et al. Standardization of the modified Rodnan skin score for use in clinical trials of systemic sclerosis. J Scleroderma Relat Disord 2017;2:11-18.

25. Ogliari C, Sed NPO, Vecchi M. High resolution manometry in sclerosis patients. Clin Gastroenterol Hepatol 2017;15:1640-1641.

26. Carlson DA, Crowell MD, Kimmel JN, et al. Loss of peristaltic reserve, determined by multiple rapid swallows, is the most frequent esophageal motility abnormality in patients with systemic sclerosis. Clin Gastroenterol Hepatol 2016;14:1502-1506.

27. Hooi JKY, Lai WY, Ng WK, et al. Global prevalence of Helicobacter pylori infection: systematic review and meta-analysis. Gastroenterology 2017;153:420-429.

28. Cheng FC, Lam SK, Ong GB. Maximum acid output to graded doses of pentagastrin and its relation to parietal cell mass in Chinese patients with duodenal ulcer. Gut 1977;18:827-832.

29. Spechler SJ, Jain SK, Tendler DA, Parker RA. Racial differences in the frequency of symptoms and complications of gastro-oesophageal reflux disease. Aliment Pharmacol Ther 2002;16:1795-1800.
30. Lahcene M, Oumnia N, Matougui N, Boudjella M, Tebaibia A, Touchene B. Esophageal involvement in scleroderma: clinical, endoscopic, and manometric features. ISRN Rheumatol 2011;2011:325826.

31. Aggarwal N, Lopez R, Gabbard S, Wadhwa N, Devaki P, Thota PN. Spectrum of esophageal dysmotility in systemic sclerosis on high-resolution esophageal manometry as defined by Chicago classification. Dis Esophagus 2017;30:1-6.

32. Kimmel JN, Carlson DA, Hinchcliff M, et al. The association between systemic sclerosis disease manifestations and esophageal high-resolution manometry parameters. Neurogastroenterol Motil 2016;28:1157-1165.

33. Bassotti G, Battaglia E, Debernardi V, et al. Esophageal dysfunction in scleroderma: relationship with disease subsets. Arthritis Rheum 1997;40:2252-2259.

34. Airò P, Della Casa D, Danieli E, Missale G, Cattaneo R, Cestari R. Oesophageal manometry in early and definite systemic sclerosis. Clin Rheumatol 2005;24:370-376.

35. Roman S, Hot A, Fabien N, et al. Esophageal dysmotility associated with systemic sclerosis: a high-resolution manometry study. Dis Esophagus 2011;24:299-304.

36. Hurwitz AL, Duranceau A, Postlethwait RW. Esophageal dysfunction and Raynaud's phenomenon in patients with scleroderma. Am J Dig Dis 1976;21:601-606.

37. Akesson A, Wollheim FA. Organ manifestations in 100 patients with progressive systemic sclerosis: a comparison between the CREST syndrome and diffuse scleroderma. Br J Rheumatol 1989;28:281-286.

38. Yarze JC, Varga J, Stampfl D, Castell DO, Jimenez SA. Esophageal function in systemic sclerosis: a prospective evaluation of motility and acid reflux in 36 patients. Am J Gastroenterol 1993;88:870-876. 